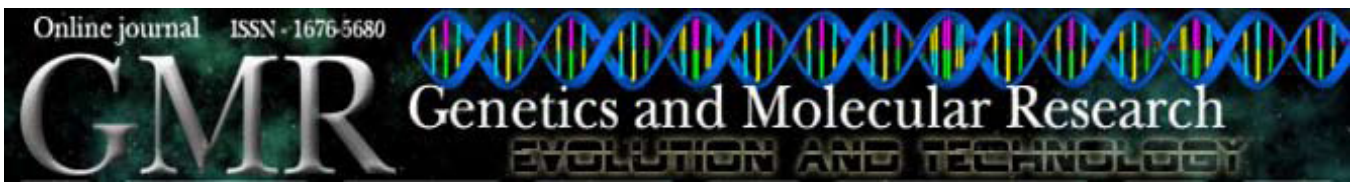

\title{
Estimation of genetic distance between 10 maize accessions with varying response to different levels of soil moisture
}

\author{
M. Aslam ${ }^{1}$, F.S. Awan' ${ }^{2}$ I.A. Khan' ${ }^{1}$ and A.I. Khan ${ }^{2}$ \\ ${ }^{1}$ Department of Plant Breeding and Genetics, \\ University of Agriculture, Faisalabad, Pakistan \\ ${ }^{2}$ Centre of Agricultural Biochemistry and Biotechnology, \\ University of Agriculture, Faisalabad, Pakistan \\ Corresponding author: F.S. Awan \\ E-mail: awanfaisal@yahoo.com
}

Genet. Mol. Res. 8 (4): 1459-1465 (2009)

Received February 25, 2009

Accepted April 13, 2009

Published December 8, 2009

\begin{abstract}
Ten maize accessions (NC-9, A50-2, M-14, B-42, NC-3, T-7, N-48-1, B-34, USSR, and WFTMS) were studied to estimate the genetic distance on molecular level by random amplified polymorphic DNA. These accessions were selected on the basis of their variable responses against different levels of moisture. Twenty-five primers were used to test genetic diversity, of which 14 were observed to be polymorphic. Ninety-three loci were amplified; among these, 77 showed polymorphism and the other 16 were monomorphic. Primers A-13 and C-02 gave the most polymorphic bands, while primers A-01 and C-06 gave the fewest polymorphic bands. The genetic similarities of the 10 maize accessions ranged from 82.8 to $54.8 \%$. Accessions USSR and WFTMS showed greatest similarity, and accessions M-14 and B-42 were found more dissimilar than the other accessions. On the basis of cluster analysis, these 10 accessions were classified in two major groups, A and B, and than further divided into sub-groups. The cluster analysis showed that ac-
\end{abstract}


cessions in the same group as well as in the sub-groups were similar in their physical and morphological characters, since the characters are controlled genetically.

Key words: Random amplified polymorphic DNA; Maize; Genetic diversity; Germplasm conservation

\section{INTRODUCTION}

A plant may experience several distinct types of abiotic stress in the field, such as water shortage, salinity, and temperature extremes, either continuously or discontinuously at different times during the growing season (Tester and Bacic, 2005). Abiotic stresses limit crop productivity (Boyer, 1982; Araus et al., 2002). Among the various abiotic stresses, drought is undoubtedly one of the man's worst natural enemies. It can occur in any region of the world, affecting man to different degrees, from slight personal inconvenience to life endangerment. Drought results in reduced crop yields, pasture deterioration and livestock mortality. It strongly affects the production of cereals and poses a serious threat to the food security of households, countries and even entire subcontinents. In the future, the destructive impact of drought may grow, as the specter of climate change becomes a reality. World food security is dependent on continuous crop improvement and, in particular, the development of crops with increased tolerance to abiotic stresses, especially drought and salinity (Katherine and Gehring, 2005). The use of genetics to improve drought tolerance and provide yield stability is an important part of the solution to this problem. However, improved genetics can be packaged in a seed and more easily be adapted than improved agricultural practices that depend more heavily on input availability, infrastructure, access to markets, and skill in crop and soil management (Campos et al., 2004).

Maize is one of the most important grain crops in the world, and it is perhaps the most versatile. It is used in the human diet in both fresh and processed forms. The valueadded concept has been an economic driver in the specialty corn markets (Hallauer and Miranda, 2000). In many regions of the world, e.g., Latin America, Africa, and Asia, maize is the staple food and sometimes the only source of protein in the diet, especially in weaning food for babies. One global food supply-demand model predicts that global demand for maize will increase from 526 to 784 million tons from 1993 to 2020, with most of the increased demand coming from developing countries (Rosegrant et al., 1999). Assuming no increase in maize production area, an annual growth rate in maize yield of approximately $1.5 \%$ will be needed to meet this demand; however, from 1982 to 1994, the yield growth rate for maize was $1.2 \%$ worldwide, but only $1 \%$ in developed countries as a group, which account for most of the maize production (Duvick and Cassman, 1999).

Maize is the third most important cereal in Pakistan after wheat and rice. It is grown on 0.98 million ha, with about $64 \%$ under irrigation. Its average production in Pakistan is 2849 $\mathrm{kg} / \mathrm{ha}$, with a total production of 3.56 million tons (Govt. of Pakistan, 2005-6). The average yield of maize in Pakistan is very low when compared to developed countries and even compared to the world average.

It would be useful to have superior lines adapted to Pakistani conditions. There are two pre-requisites for developing new lines; one is the existence of variation for the character and 
second is heritability. Genetically controlled variation for drought tolerance can enable plant breeders to develop drought tolerant maize lines. Based on previous research, it is evident that variation for drought tolerance exists in various crop species, including wheat (Guttieri et al., 2001), sunflower (Krampitz et al., 1984), barley (Ceccarelli et al., 1987), and maize (Frova et al., 1999). Because of this rich genetic diversity for drought tolerance, new methodologies can help to evolve drought tolerant varieties. Hybrids of parents having more diversity yield better results than similar parents (Troyer et al., 1988).

The usefulness of these concepts for the characterization of an inbred for crosses has made them increasingly popular among maize breeders during the last decades. A series of combining ability studies have been made by many workers from the International Maize and Wheat Improvement Center (CIMMYT) to establish heterotic patterns among several maize populations and gene pools and to maximize their yield for hybrid development (Crossa et al., 1990; Beck et al., 1990, 1991; Vasal et al., 1992). Plant breeders working with several species reported a direct relationship between the level of heterosis exhibited by the F1 and the divergence between their parents (Lee et al., 1989; Sekhon and Gupta, 1995). Therefore, estimation of genetic distance can be useful for prediction of high performance crossings (Smith et al., 1990).

The utilization of genetics for the improvement of drought tolerance and for yield stability is an important part of the solution to improve global maize production (Campos et al., 2004). Because of genetic complexity of drought tolerance, it is the most difficult trait to improve through conventional plant breeding. The challenge is even greater for developing drought tolerant plants for water-limited environments where the occurrence, timing, and severity of drought may fluctuate from year to year. To overcome this problem, extensive work has been done in the disciplines of breeding, physiology, agronomy, and recently in biotechnology. Among biotechnological efforts, the focus has been on the genetic dissection of drought tolerance through the identification of quantitative trait loci associated with yield components. After much study about the complexity of drought, it is clear that a multidisciplinary approach including breeding, physiology and biotechnology is required for efficient germplasm improvement for greater drought tolerance in maize. Since the application of different breeding techniques is time consuming and expensive, the use of molecular markers is recently being advocated as a viable alternative approach (Joyce et al., 1999). Molecular markers have been used to calculate genetic distance in maize (Smith et al., 1990). Molecular markers based on polymorphisms of the DNA are especially useful because they are not affected by the environment. Random amplified polymorphic DNA (RAPD) has widely used to quantify the genetic variation, due to its simplicity and power to detect differences, even in closely related individuals. We examined heterotic effects and combining ability among screened germplasms and looked for suitable RAPD bands as markers for drought tolerance.

\section{MATERIAL AND METHODS}

\section{Plant material}

The 10 accessions, namely NC-9, A50-2, M-14, B-42, NC-3, T-7, N-48-1, B-34, USSR, and WFTMS, were selected because they vary in their physiological response to dif- 
ferent levels of moisture. Five accessions had been found to have a highest level of tolerance and five accessions were considered to be susceptible (Aslam et al., 2006).

\section{DNA isolation}

All the accessions were planted in pots in a growth chamber (C-606, C.E. Ltd. Willipeg Manitoba, Canada). Total genomic DNA was extracted by the modified CTAB method (Khan et al., 2004). The concentrations of genomic DNA samples were measured using a spectrophotometer (CECIL CE 2021, 2000 Series, Cambridge, UK). The quality of the DNA was checked by running it on $0.8 \%$ agarose gel with $0.5 \mathrm{X}$ TBE buffer. The DNA samples giving smears in the gel were rejected. Concentrations of $\mathrm{MgCl}_{2}, \mathrm{Taq}$ DNA polymerase and of template DNA were optimized for polymerase chain reaction (PCR) conditions.

\section{RAPD analysis}

Then, PCR was run in a thermal cycler (Eppendorf AG No. 533300839, Germany) with $15 \mathrm{ng}$ DNA as a template. Amplification reactions contained 1.0 U Taq DNA polymerase (MBI, Fermentas, Vilnius, Lithuania), $50 \mathrm{mM} \mathrm{KCl}, 3 \mathrm{mM} \mathrm{MgCl}, 100 \mathrm{mM}$ each of dNTPs, 0.2 M decamer primer (Gene Link Company, Hawthorne, NY, USA). The DNA amplification protocol was $94^{\circ} \mathrm{C}$ for $5 \mathrm{~min}$, followed by 40 cycles of $94^{\circ} \mathrm{C}$ for $1 \mathrm{~min}$, $36^{\circ} \mathrm{C}$ for $1 \mathrm{~min}, 72^{\circ} \mathrm{C}$ for $2 \mathrm{~min}$, and finally $72^{\circ} \mathrm{C}$ for $10 \mathrm{~min}$. All amplification products were electrophoresed on $1.2 \%(\mathrm{w} / \mathrm{v})$ agarose gels at $80 \mathrm{~V}$ for $2 \mathrm{~h}$, stained with ethidium bromide, visualized in a UV transilluminator at $300 \mathrm{~nm}$ and photographed in a gel doc System (SynGen, Synoptics Ltd., UK).

\section{Data analysis}

The DNA fragments amplified by a given primer were scored as present (1) or absent (0). Both monomorphic and polymorphic primers were included in the analysis, and only reproducible fragments were considered. Coefficients of similarity among cultivars were calculated according to Nei and Li (1979). A dendrogram based on these similarity coefficients was constructed by using unweighted pair group method of arithmetic means (UPGMA). This similarity matrix was analyzed using NTSYS-pc 2.01 and clustered with an UPGMA average algorithm to determine the genetic relationships among the 10 maize genotypes.

\section{RESULTS AND DISCUSSION}

Twenty five random primers were used to test genetic diversity among the 10 maize accessions, of which 14 were observed to be polymorphic. The 14 polymorphic primers along with their sequences are shown in Table 1. Ninety-three loci were amplified, with an average of 6.64 loci per primer; 77 loci showed polymorphism; the other 16 were monomorphic in all 10 maize accessions. On average, each primer gave 5.5 polymorphic bands. Primers GLA-13 and GLC-02 gave the largest number of polymorphic bands, which was nine, followed by primers A-08 and C-11, both with seven polymorphic bands. Primers GLA-01 and GLC-06 gave the fewest polymorphic bands, two and three, respectively. 


\begin{tabular}{|c|c|c|c|c|c|}
\hline S. No. & Primer & Sequence & Amplified loci & Polymorphic loci & Polymorphic loci (\%) \\
\hline 1 & GL DecamerA-01 & CAGGCCCTTC & 3 & 2 & $66.67 \%$ \\
\hline 2 & GL DecamerA-02 & TGCCGAGCTG & 7 & 6 & $85.71 \%$ \\
\hline 3 & GL DecamerA-08 & GTGACGTAGG & 7 & 7 & $100 \%$ \\
\hline 4 & GL DecamerA-09 & GGGTAACGCC & 5 & 4 & $80 \%$ \\
\hline 5 & GL DecamerA-13 & CAGCACCCAC & 9 & 9 & $100 \%$ \\
\hline 6 & GL DecamerA-16 & AGCCAGCGAA & 7 & 6 & $85.71 \%$ \\
\hline 7 & GL DecamerA-17 & GACCGCTTGT & 4 & 4 & $100 \%$ \\
\hline 8 & GL DecamerB-07 & GGTGACGCAG & 8 & 5 & $62.50 \%$ \\
\hline 9 & GL DecamerB-11 & GTAGACCCGT & 7 & 5 & $71.43 \%$ \\
\hline 10 & GL DecamerC-02 & GTGAGGCGTC & 9 & 9 & $100 \%$ \\
\hline 11 & GL DecamerC-06 & GAACGGACTC & 4 & 3 & $75 \%$ \\
\hline 12 & GL DecamerC-11 & AAAGCTGCGG & 9 & 7 & $77.78 \%$ \\
\hline 13 & GL DecamerC-15 & GACGGATCAG & 6 & 4 & $66.67 \%$ \\
\hline 14 & GL DecamerD-19 & CTGGGGACTT & 8 & 6 & $75 \%$ \\
\hline
\end{tabular}

The genetic similarity matrix of RAPD data for the 10 maize accessions was constructed based on Nei and Li's (1979) coefficient of similarity and is shown in Table 2. The genetic similarities of the 10 accessions ranged from 82.8 to $54.8 \%$. The lines USSR and WFTMS had the greatest similarity. These two lines differed from each other only in 17 bands with 14 different primers. Genetic similarity between lines N-48-1 and NC-3 was the second highest (77.4\%). Accessions M14 and B-42 were found genetically more dissimilar than the other accessions; they scored 54.8\% similarity, followed by A50-2 and B-34 and NC-9 and USSR, which showed $57.0 \%$ similarity.

\begin{tabular}{|c|c|c|c|c|c|c|c|c|c|c|}
\hline Accession & NC-9 & NC-3 & B-34 & $\mathrm{N}-48-1$ & $\mathrm{~T}-7$ & B-42 & WFTMS & USSR & A50-2 & M-14 \\
\hline NC-9 & 1 & 0.7204 & 0.6129 & 0.6882 & 0.6667 & 0.6667 & 0.6129 & 0.5699 & 0.7204 & 0.6882 \\
\hline $\mathrm{NC}-3$ & & 1 & 0.7419 & 0.7742 & 0.6452 & 0.6667 & 0.6774 & 0.7204 & 0.6989 & 0.7312 \\
\hline B-34 & & & 1 & 0.6882 & 0.6237 & 0.6022 & 0.6129 & 0.6344 & 0.5699 & 0.6022 \\
\hline N-48-1 & & & & 1 & 0.7204 & 0.6774 & 0.6452 & 0.6237 & 0.6452 & 0.6989 \\
\hline T-7 & & & & & 1 & 0.6989 & 0.7097 & 0.6882 & 0.7097 & 0.6774 \\
\hline B-42 & & & & & & 1 & 0.6452 & 0.6452 & 0.7312 & 0.5484 \\
\hline WFTMS & & & & & & & 1 & 0.828 & 0.6344 & 0.6452 \\
\hline USSR & & & & & & & & 1 & 0.5914 & 0.5806 \\
\hline A $50-2$ & & & & & & & & & 1 & 0.7527 \\
\hline M-14 & & & & & & & & & & 1 \\
\hline
\end{tabular}

Cluster analysis based on similarity values classified the 10 maize accessions into two different major groups (Figure 1). These two major groups were further divided into subgroups. The first major group consisted of 6 accessions and the second had 4 . Accessions that were present in the same sub-group were more similar on a molecular basis than others. For example, accessions USSR and WFTMS had the greatest similarity $(82.8 \%)$ and were grouped together in sub-group B2, followed by $77.4 \%$ similarity shown by $\mathrm{NC}-3$ and $\mathrm{N}-48-1$, which were grouped in group A. M-14 and B-42 showed lowest similarity value (54.8\%) and were grouped into different major groups, followed by NC-9 and USSR, which showed 57.0\% simi- 
larity and were grouped in different groups. Cluster analysis also showed that accessions in the same group as well as in the same sub-group were similar in their physical and morphological characters, as the characters were controlled genetically.

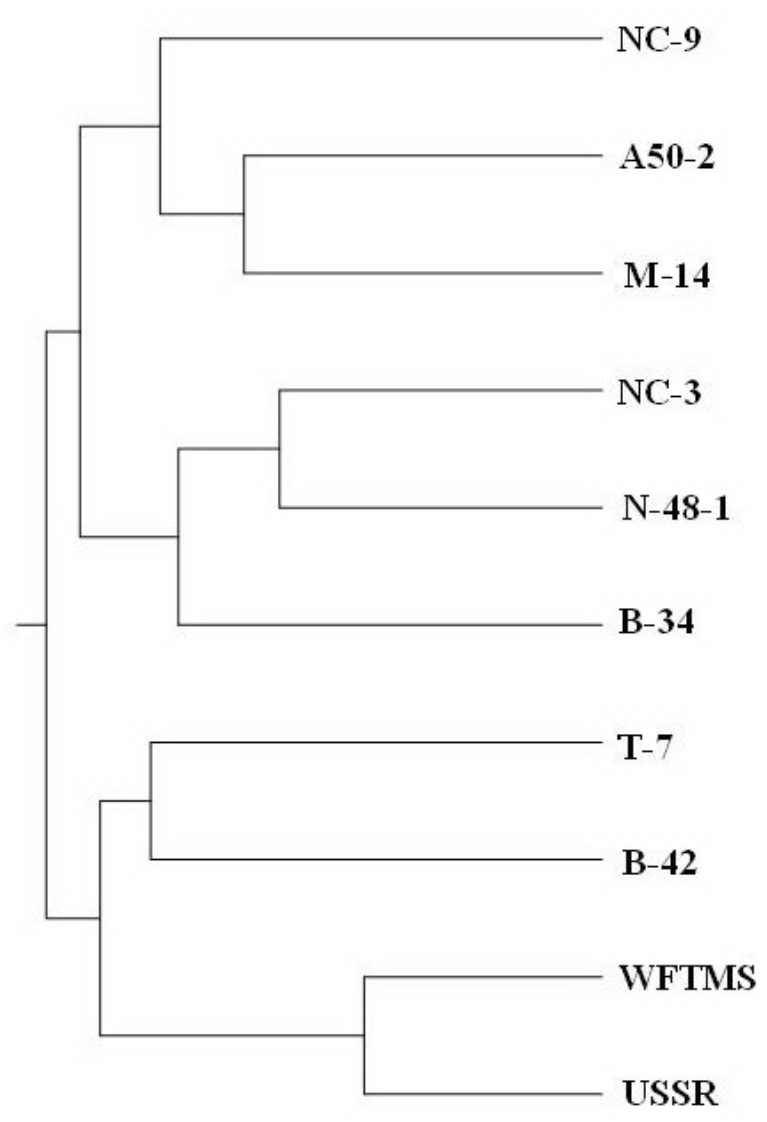

Figure 1. Genetic distance of 10 maize accessions developed from RAPD data using unweighted pair group of arithmetic means (UPGMA).

We, therefore, concluded that in spite of the relatively low level of genetic variation present in the maize genotypes, RAPD can be used as a reliable technique for genotype identification as well as interspecific variation. Thus, by judicious augmentation of these systems of evaluation, rapid progress can be achieved in developing maize genotypes with important quality parameters.

\section{ACKNOWLEDGMENTS}

We thank the staff of Center of Agricultural Biochemistry and Biotechnology, for technical and financial support for this research. 


\section{REFERENCES}

Araus JL, Slafer GA, Reynolds MP and Royo C (2002). Plant breeding and drought in C3 cereals: what should we breed for? Ann. Bot. 89 (Spec. No.): 925-940.

Aslam M, Khan IA, Saleem M and Ali Z (2006). Assessment of water stress tolerance in different maize accessions at germination and early growth stage. Pak. J. Bot. 38: 1571-1579.

Beck DL, Vassal SK and Crossa J (1990). Heterosis and combining ability of CIMMYT's tropical early and intermediate maturity maize (Zea mays L.) germplasm. Maydica 35: 279-285.

Beck DL, Bassal SK and Crosa J (1991). Heterosis and combining ability among subtropical and temperate intermediatematurity maize germplasm. Crop Sci. 31: 68-73.

Boyer JS (1982). Plant productivity and environment. Science 218: 443-448.

Campos H, Cooper M, Habben JE, Edmeades GO, et al. (2004). Improving drought tolerance in maize: a view from industry. Field Crops Res. 90: 19-34.

Ceccarelli S, Grando S and van Leur JAG (1987). Genetic diversity in barley landraces from Syria and Jordan. Euphytica 36: 389-405.

Crossa J, Vasal SK and Beck DL (1990). Combining ability estimates of CIMMYT's tropical late yellow maize germplasm [in Mexico]. Maydica 35: 273-278.

Duvick DN and Cassman KG (1999). Post-green revolution trends in yield potential of temperate maize in the NorthCentral United States. Crop Sci. 39: 1622-1630.

Frova C, Krajewski G, di Fonzo N, Villa M, et al. (1999). Genetic analysis of drought tolerance in maize by molecular markers. I. Yield components. Theor. Appl. Genet. 99: 280-288.

Guttieri MJ, Jeffrey C, O’Brien SK and Souza E (2001). Relative sensitivity of spring wheat grain yield and quality parameters to moisture deficit. Crop Sci. 41: 327-335.

Hallauer AR and Miranda JB (2000). Quantitative Genetics in Maize Breeding. 3rd edn. Iowa State University Press, Ames.

Joyce TA, Abberton TM, Michaelson-Yeates TPT and Forster JW (1999). Relationships between genetic distance measured by RAPD-PCR and heterosis in inbred lines of white clover (Trifolium repens L.). Euphytica 107: 159-165.

Katherine D and Gehring C (2005). Engineering drought and salinity tolerance in plants: lessons from genome-wide expression profiling in Arabidopsis. Trends Biotech. 23: 547-552.

Khan IA, Awan FS, Ahmad A and Khan AA (2004). A modified mini-prep method for economical and rapid extraction of genomic DNA in plants. Plant Mol. Biol. Rep. 22: 89a-89e.

Krampitz MJ, Klug K and Fock HP (1984). Rates of photosynthetic $\mathrm{CO}_{2}$ uptake, photorespiratory $\mathrm{CO}_{2}$ evolution and dark respiration in water stressed sunflower and bean leaves. Photosynthetica 18: 329-337.

Lee M, Godshalk EB, Lamkey KR and Woodman WW (1989). Association of restriction fragment length polymorphisms among maize inbreds with agronomic performance of their crosses. Crop Sci. 29: 1067-1071.

Nei M and Li WH (1979). Mathematical model for studying genetic variation in terms of restriction endonucleases. Proc. Natl. Acad. Sci. U. S. A. 76: 5269-5273.

Rosegrant MW, Leach N and Gerpacio RV (1999). Alternative futures for world cereal and meat consumption. Proc. Nutr. Soc. 58: 219-234.

Sekhon MS and Gupta VP (1995). Genetic distance and heterosis in Indian mustard: developmental isozymes as indicators of genetic relationships. Theor. Appl. Genet. 91: 1148-1152.

Smith OS, Smith JSC, Bowen SL, Tenborg RA, et al. (1990). Similarities among a group of elite maize inbreds as measured by pedigree, F1 grain yield, grain yield, heterosis, and RFLPs. Theor. Appl. Genet. 80: 833-840.

Tester M and Bacic A (2005). Abiotic stress tolerance in grasses. From model plants to crop plants. Plant Physiol. 137: 791-793.

Troyer AF, Openshaw SJ and Knittle KH (1988). Measurement of genetic diversity among popular commercial corn hybrids. Crop Sci. 28: 481-485.

Vasal SK, Srinivasan G, Crosa J and Beck DL (1992). Heterosis and combining ability of CIMMYT's subtropical and temperate early-maturity maize germplasm. Crop Sci. 32: 884-890. 